\title{
Desorption kinetics of PCP-contaminated soil: effect of temperature
}

\author{
Ken K.C. Tse*, Shang-Lien Lo \\ Institute of Environmental Engineering, National Taiwan University, Taipei, Taiwan, ROC
}

Received 4 April 2000; received in revised form 19 March 2001; accepted 12 April 2001

\begin{abstract}
A thermally enhanced pump-and-treatment method for pentachlorophenol (PCP)-contaminated soil and groundwater has shown potential advantages over the traditional pump-and-treatment method. Studies on the desorption kinetics of PCP from aquifer soil are the first step toward quantitative assessment of the newly proposed method. Five series of desorption batch tests were conducted at different temperatures, and the test results were analyzed by linear regression to determine the best-fit kinetic model for PCP desorbed from the contaminated field soil under all temperature conditions. The first-order kinetic model, parabolic diffusion model, and modified Freundlich model were discussed in linear regression work. A modified Freundlich model was found to describe the PCP desorption kinetics from soil in consideration of a temperature effect. (C) 2001 Elsevier Science Ltd. All rights reserved.
\end{abstract}

Keywords: PCP; Thermal desorption kinetics; Steam injection; Thermally enhanced pump-and-treatment

\section{Introduction}

The widespread use of pentachlorophenol (PCP) has created tremendous amounts of soil contamination and groundwater problems in the world. The global production of PCP is upwards of 50 million $\mathrm{kg}$, and about $80 \%$ of this is used in the protection and preservation of wood [1]. There are approximately 470 wood preserving facilities in the US, most of which have PCP contamination problems. In Taiwan, there are also several PCP sites that need to be decontaminated. One of these contaminated sites is currently under remediation. Steam injection is one of the several proposed methods to remediate this site.

The strong affinity of most chlorinated organic compounds like PCP to the soil matrix in aquifers has been known to reduce dramatically the remedial efficiency of the traditional pump-and-treatment method. At Koppers Texarkana plant, a US EPA Superfund site, it was estimated that $\$ 12.4$ million would be needed

\footnotetext{
*Corresponding author. Fax: + 886-2-239-63505.

E-mail address: ktse@ms17.hinet.net (K.K.C. Tse).
}

to amend remedial actions for 30 years [2]. The traditional pump-and-treatment process has been proven to be a time consuming process. The idea of a thermally enhanced pump-and-treatment method was then introduced to expedite the process of pump and treatment. By injecting steam, groundwater temperature is raised thereby increasing the solubility of PCP in water. Studies by Archard et al. [3] showed that the solubility of PCP in water is $21.4 \pm 1 \mathrm{mg} / \mathrm{L}$ at $25.1^{\circ} \mathrm{C}$ and $86.2 \pm 2 \mathrm{mg} / \mathrm{L}$ at $46.8^{\circ} \mathrm{C}$. PCP tends to show preference for the aqueous phase than the soil matrix when the temperature is raised and is removed faster when steam is injected into the aquifer. Other methods of raising groundwater temperature like electrode soil heating, hot water injection or hot air injection, should also benefit the progress of remedial pump-and-treatment work. When applying any soil heating technique, understanding the kinetics of PCP desorption from soil into water is essential to assess the process of thermally enhanced pump and treatment. Several studies of steam enhanced extraction to remove volatile organic compounds (VOCs) have been performed and have indicated great removal rates $[4,5]$, but very few studies have 
investigated the removal of semi-volatile organic compounds (SVOCs) like PCP by thermally enhanced extraction.

You and Liu [6] studied the effects of solution $\mathrm{pH}$ on desorption isotherms of PCP in soil. They found that desorption of PCP was enhanced when the solution changed from acidic to neutral $\mathrm{pH}$. For example, at $\mathrm{pH}$ $3.0,80 \%$ of PCP was adsorbed in soil. At $\mathrm{pH}$ greater than 7.0 , less than $20 \%$ of PCP was adsorbed. They confirmed that protonated PCP tended to be adsorbed by soil and that acidity enhances adsorption because acidic solutions protonate PCP. Mollah and Robinson [7] studied the adsorption isotherms of PCP by activated carbon and found an Arrhenius-type relationship for various ranges of temperature.

The PCP-contaminated site in Tainan, Taiwan, is currently under a feasibility study. Injecting steam into the aquifer to heat the soil matrix seems to be a promising remedial method. By developing the formulas of desorption kinetics of PCP from soil, we are able to understand the relationships of PCP concentration to temperature and time. The formulas can then be combined into a numerical model, which is still under development, for steam injection.

\section{Theory}

PCP is a weak monoprotic organic acid. It dissociates in water when the $\mathrm{pH}$ is higher than $\mathrm{p} K_{\mathrm{a}}$, the equilibrium constant. The dissociation reaction can be written as $[1,8]$

$$
\mathrm{C}_{6} \mathrm{Cl}_{5} \mathrm{OH} \leftrightarrow \mathrm{C}_{6} \mathrm{Cl}_{5} \mathrm{O}^{-}+\mathrm{H}^{+}, \quad \mathrm{p} K_{\mathrm{a}}=4.75 \text { at } 25^{\circ} \mathrm{C} .
$$

The distribution ratio of PCP adsorbed in the soil to PCP dissolved in the aqueous phase can be expressed as $[7,8]$

$K=\frac{\left[\mathrm{C}_{6} \mathrm{Cl}_{5} \mathrm{OH}\right]_{\mathrm{s}}+\left[\mathrm{C}_{6} \mathrm{Cl}_{5} \mathrm{O}^{-}\right]_{\mathrm{s}}}{\left[\mathrm{C}_{6} \mathrm{Cl}_{5} \mathrm{OH}\right]_{\mathrm{w}}+\left[\mathrm{C}_{6} \mathrm{Cl}_{5} \mathrm{O}^{-}\right]_{\mathrm{w}}}$,

where the subscript s represents the soil phase and $\mathrm{w}$ represents the aqueous phase.

Cristodoulatos and Mohiuddin [8] studied the effects of soil and solution properties on the sorption of PCP by natural soils. Five types of soils were used in the batch tests of PCP adsorption isotherms. Cation exchange capacity $(\mathrm{CEC})$, ratio of organic carbon $\left(f_{\mathrm{oc}}\right)$, percent of fine grains in soil $(f)$, and soil to solution ratio $(S S)$ were measured for each type of soil. Through correlation analysis of these soil characteristics and solution $\mathrm{pH}$ values, they proposed an empiric equation for $K$ :

$K=\frac{213.8(\mathrm{SS})^{0.09}(\mathrm{CEC})^{1.09}(f)^{-0.6}\left(f_{\mathrm{oc}}\right)^{0.47}}{1+10^{\mathrm{pH}-4.75}}$.

Among these five parameters, the $\mathrm{pH}$ of the aqueous solution obviously dominates the distribution ratio when $\mathrm{pH}$ is higher than 4.75 , as predicted by many researchers [6,9].

Mollah and Robinson [7] studied the adsorption isotherms of PCP by activated carbon. They found the best-fit isotherm model when $\mathrm{pH}$ ranged from 6 to 11 and temperature ranged from $10^{\circ} \mathrm{C}$ to $60^{\circ} \mathrm{C}$ :

$q=155 \mathrm{e}^{625.5 / T}(\mathrm{pH})^{-0.795} C$,

where $q$ is the concentration of PCP adsorbed on activated carbon and $C$ the concentration of PCP in the aqueous phase. The adsorption energy was $5.2 \mathrm{~kJ} / \mathrm{mol}$. Eq. (4) actually shows an Arrhenius-type relationship for temperature. It was confirmed that raising the temperature would enhance desorption of PCP from activated carbon. We thus speculated that PCP in soil would also follow the same type of relationship when temperature varies.

Many adsorption and desorption kinetic equations have been used by researchers [10-12]. Among these models, three kinetic models are often used:

first-order kinetic model

$\log X=k_{d} t$,

modified Freundlich model

$Q=k C_{0} t^{1 / m}$,

parabolic diffusion model

$X=D t^{1 / 2}+$ constant,

where $X$ is the ratio of mass adsorbed in soil, $k_{\mathrm{d}}$ the apparent desorption rate coefficient, $t$ the time lapse, $Q$ the concentration in soil phase, $C_{0}$ the initial concentration in aqueous phase, $k$ the adsorption or desorption rate coefficient, $m$ a constant and $D$ the overall diffusion constant. Eq. (6) was previously used to model adsorption kinetics [12]. Dividing both sides of Eq. (6) by $C_{0}$, we obtained the desorption model:

$X=k t^{1 / m}$

The first-order kinetic model has been often used to describe film diffusion-controlled reactions [12]. Conformity to the parabolic diffusion model also suggests a diffusion-controlled process and that either intraparticle diffusion or surface diffusion is rate limiting [12]. Conformity to the modified Freundlich model suggests that the energy of adsorption decreases exponentially with increasing surface saturation $[12,13]$. Interactions between the adsorbates may explain the decreasing energy of adsorption with increasing surface saturation. For adsorbed adsorbates, a decrease in the distance between two adsorbed adsorbates increases the perturbation potential [10]. At low surface saturation, the adsorbed adsorbates tend to locate themselves so that they have a minimum potential energy and require maximum adsorption energy. With increasing adsorption, the distance between the adsorbed adsorbates 
decreases and the perturbation energy as well as the total potential energy of the adsorbed adsorbates increases so that the adsorption energy is reduced [13]. The modified Freundlich model describes an initial rapid adsorption reaction and decreasing adsorption rate with prolonged reaction time. The initial rapid reaction rate has a high adsorption energy associated with low surface saturation. The slow reaction rate with prolonged time is assumed to be the result of increased surface negative charge, increased interaction potential, and decreased adsorption energy [13].

\section{Methods and materials}

The soil used in the tests came from Tainan, Taiwan, where a field steam injection pilot test was being conducted. The soil was classified as gray silty sand and identified to be free of PCP before use as the test material. The percent of fine grains in the soil was $13 \%$. The porosity, total organic carbon, and cation exchange capacity of the soil were $0.34,6700 \mathrm{mg} / \mathrm{kg}$, and $2.1 \mathrm{meq} /$ $100 \mathrm{~g}$, respectively. Clean soil was air-dried at room temperature and then passed through a 2-mm sieve before use. Pure PCP powder was purchased from SIGMA. To prepare the PCP-spiked soil, $5 \mathrm{~mL}$ of $121.5 \mathrm{mg} / \mathrm{L}$ PCP in acetone was mixed with $10 \mathrm{~g}$ of soil. The spiked soil was vented for $16 \mathrm{~h}$ to let the acetone vaporize. The soil was then placed into a $20-\mathrm{mL}$ brown glass vial and closed with a Teflon-lined cap for 3 days to allow enough time for PCP to be adsorbed onto the soil matrix. A total of $30 \mathrm{~g}$ soil was prepared. Three soil samples were analyzed to give an average soil concentration of $48.8 \mathrm{mg} / \mathrm{kg}$ and standard deviation of $1.8 \mathrm{mg} / \mathrm{kg}$.

Five groups of soil samples were prepared for batch temperatures of $30^{\circ} \mathrm{C}, 45^{\circ} \mathrm{C}, 60^{\circ} \mathrm{C}, 75^{\circ} \mathrm{C}$, and $90^{\circ} \mathrm{C}$. Spiked soil $(0.50 \mathrm{~g})$ was weighed and placed into each $15 \mathrm{~mL}$ brown glass vial. Sodium perchlorinate $(0.01 \mathrm{~N})$ was prepared by diluting equal parts of $0.1 \mathrm{~N}$ perchlorine and $0.1 \mathrm{~N}$ sodium hydroxide to milli-Q water. The final solution $\mathrm{pH}$ was adjusted to 7.0 with $0.1 \mathrm{~N}$ perchlorine and $0.1 \mathrm{~N}$ sodium hydroxide. Sodium perchlorinate solution can also help to stabilize ionic strength, in addition to $\mathrm{pH}$ adjustment.

At the start of the batch tests, approximately $15 \mathrm{~mL}$ of $0.01 \mathrm{~N}$ sodium perchlorinate solution was added to each vial of soil sample. No headspace was allowed in any vials so that the PCP could not vaporize when the temperature was raised. The actual amount of solution added was determined by weighing each vial and subtracting the weight of the soil from the vial. Immediately after the solution was poured into each vial, the vial was closed with a Teflon-lined silicone and aluminum cap and was placed in an oven at a preset temperature. For each group of vials, one vial was taken out of the oven for PCP concentration analysis at appropriate time periods.

Solution samples were taken from the vials using syringe needles. Each sample was filtrated through a 0.2m PVDF syringe filter (MILLEX). To ensure complete transformation of PCP into molecular form, the $\mathrm{pH}$ of the filtered solution was lowered to less than 2.0 by adding $1 \mathrm{~mL}$ of $0.1 \mathrm{~N}$ nitric acid. The solution was then extracted with hexane and analyzed by GC-ECD. After decanting the solution, $2 \mathrm{~g}$ of $\mathrm{Na}_{2} \mathrm{SO}_{4}$ and $10 \mathrm{~mL}$ of ethanol was added to the vials and the solution was ultrasonically extracted for $9 \mathrm{~min}$. The extract was filtrated through a $0.2-\mathrm{m}$ PVDF syringe filter. The filtered solution was mixed with 2-propanol at a ratio of $1: 10(\mathrm{v} / \mathrm{v})$ and analyzed by GC-ECD. The residual water content of soil in each decanted vial was assumed to be saturated. Therefore, the real soil concentrations were obtained by subtracting the mass in residual water from the total mass determined by GC-ECD. The recovery of extraction and analysis for this particular soil was $98 \%$.

The gas chromatograph used was HP 5890 Series II Plus, using an HP-5MS, $30 \mathrm{~m} \times 0.25 \mathrm{~mm} \times 0.25 \mathrm{~m}$ capillary column. The sample size was 11 in the splitless mode. The operation conditions were the following: $\mathrm{N}_{2}$ carrier gas flow rate $=2.0 \mathrm{~mL} / \mathrm{min}$; temperature program $=80^{\circ} \mathrm{C}-310^{\circ} \mathrm{C}$ at $10^{\circ} \mathrm{C} / \mathrm{min}$, held at $310^{\circ} \mathrm{C}$ for $7 \mathrm{~min}$; injector temperature $=270^{\circ} \mathrm{C}$; and detector temperature $=320^{\circ} \mathrm{C}$.

\section{Results and discussion}

The results of PCP analysis for the soil and aqueous phases are shown in Table 1. PCP concentrations in the soil phase were adjusted to obtain the real concentrations by subtracting the PCP mass in the residual water phase. Mass balance was performed by adding the residual PCP adsorbed in soil and the mass in the aqueous phase to give the original soil concentration for each vial. The calculated average original soil concentration was $37.2 \mathrm{mg} / \mathrm{kg}$ with a standard deviation of $12.9 \mathrm{mg} / \mathrm{kg}$.

The results of mass balance were acceptable for PCP [14], but it was noticed that the average original soil concentration was $23 \%$ less than the concentration determined prior to batch tests. The reduction in soil concentration may have contributed to mechanisms like biodegradation, photolysis, or vaporization of PCP during the tests. Considering the handling difficulties encountered when the soil temperature was raised, this amount of reduction seemed to be reasonable. It was very difficult to quantify the amount of reduction by each mechanism because the effects of temperature on these mechanisms have not yet been reported. To disregard the uncertainties due to these mechanisms, 
Table 1

Results of PCP desorption kinetic batch tests (concentration units of PCP in soil and aqueous phase are $\mathrm{mg} / \mathrm{kg}$ and $\mathrm{mg} / \mathrm{L}$, respectively)

\begin{tabular}{|c|c|c|c|c|c|c|}
\hline \multirow[t]{2}{*}{ Time lapse (h) } & \multirow[t]{2}{*}{ Phases } & \multicolumn{5}{|c|}{ Temperature of batch tests } \\
\hline & & $30^{\circ} \mathrm{C}$ & $45^{\circ} \mathrm{C}$ & $60^{\circ} \mathrm{C}$ & $75^{\circ} \mathrm{C}$ & $90^{\circ} \mathrm{C}$ \\
\hline \multirow[t]{2}{*}{0.5} & Soil & 46.5 & 33.4 & 36.4 & 20.4 & 22.2 \\
\hline & Aqueous & 0.61 & 0.21 & 0.40 & 0.55 & 0.40 \\
\hline \multirow[t]{2}{*}{1} & Soil & - & 18.4 & 19.9 & 20.1 & 14.6 \\
\hline & Aqueous & - & 0.51 & 0.52 & 0.55 & 0.63 \\
\hline \multirow[t]{2}{*}{2} & Soil & 40.0 & 15.3 & 14.2 & 10.4 & 9.7 \\
\hline & Aqueous & 0.80 & 0.37 & 0.77 & 1.21 & 0.77 \\
\hline \multirow[t]{2}{*}{4} & Soil & - & 9.4 & 12.9 & 8.5 & 10.4 \\
\hline & Aqueous & - & 0.52 & 0.64 & 1.19 & 0.93 \\
\hline \multirow[t]{2}{*}{8} & Soil & 19.4 & 9.1 & 11.5 & 8.7 & 8.9 \\
\hline & Aqueous & 0.70 & 0.37 & 0.90 & 1.11 & 0.72 \\
\hline \multirow[t]{2}{*}{16} & Soil & - & 6.5 & - & 4.1 & - \\
\hline & Aqueous & - & 0.41 & - & 0.80 & - \\
\hline \multirow[t]{2}{*}{24} & Soil & 11.0 & 4.2 & 10.2 & 1.9 & 2.8 \\
\hline & Aqueous & 0.91 & 0.44 & 1.64 & 0.55 & 1.00 \\
\hline \multirow[t]{2}{*}{48} & Soil & 8.2 & 3.1 & 9.8 & 2.1 & 3.3 \\
\hline & Aqueous & 1.01 & 0.51 & 1.91 & 0.96 & 1.01 \\
\hline
\end{tabular}

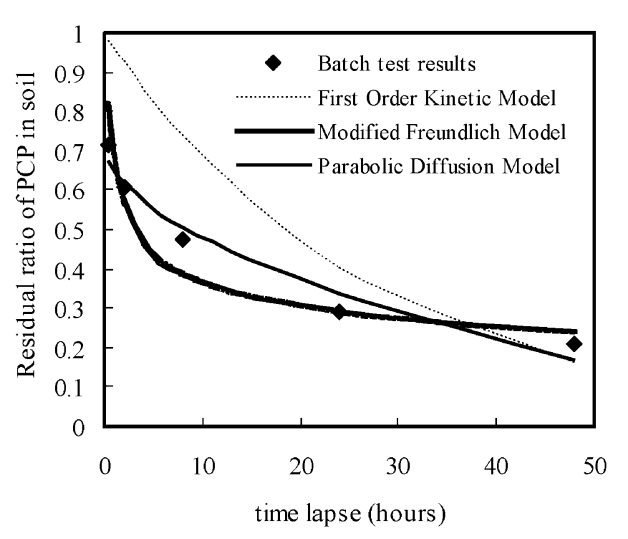

Fig. 1. PCP desorption curve at $T=30^{\circ} \mathrm{C}$

the residual PCP ratio in the soil was computed at the base of total amount of PCP in the soil and aqueous phases for each individual vial.

The batch tests for each temperature were conducted at different time periods. The test was performed first at $30^{\circ} \mathrm{C}$ with five test vials and then at $60^{\circ} \mathrm{C}$ and $90^{\circ} \mathrm{C}$ with seven vials each. Tests at $45^{\circ} \mathrm{C}$ and $75^{\circ} \mathrm{C}$ were performed later with more vials to fill in the time interval.

Figs. 1-5 show the residual mass ratio of PCP adsorbed on soil with time at temperatures $30^{\circ} \mathrm{C}$, $45^{\circ} \mathrm{C}, 60^{\circ} \mathrm{C}, 75^{\circ} \mathrm{C}$, and $90^{\circ} \mathrm{C}$, respectively. These figures showed that a higher temperature increased the rate of PCP desorption. When the temperature was $30^{\circ} \mathrm{C}$, desorption reached equilibrium after $48 \mathrm{~h}$ and the final residual mass ratio was approximately 0.2 . At $90^{\circ} \mathrm{C}$, desorption reached equilibrium after $24 \mathrm{~h}$ and the final

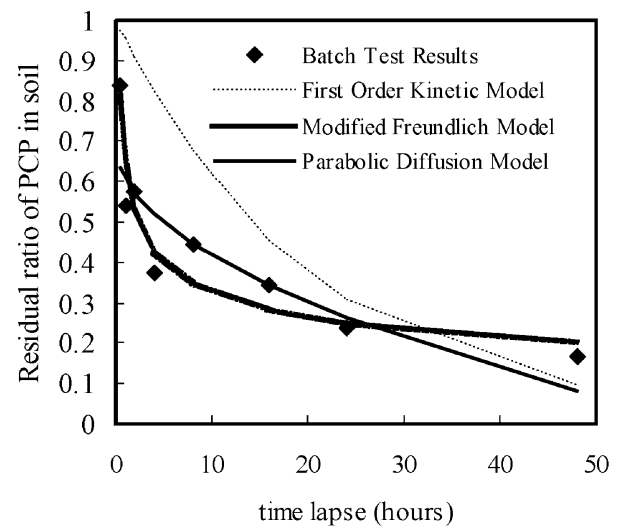

Fig. 2. PCP desorption curve at $T=45^{\circ} \mathrm{C}$.

residual mass ratio was approximately 0.09. Temperature effects were obvious when the temperature was raised above $60^{\circ} \mathrm{C}$.

The results of the batch tests were analyzed by linear regression with these three models, shown in Figs. 1-5. The conformity between the experimental data and the fit values of the model was expressed by the coefficient of determination $\left(r^{2}\right)$. All $r^{2}$ values for the three kinetic models at the five temperatures are shown in Table 2.

The first-order kinetic model did not show any correlation with the experimental data according to the low $r^{2}$ values. Even worse, when the temperature was raised above $60^{\circ} \mathrm{C}$, negative $r^{2}$ values were obtained. The poor conformity between the experimental data and the first-order model may indicate that film 


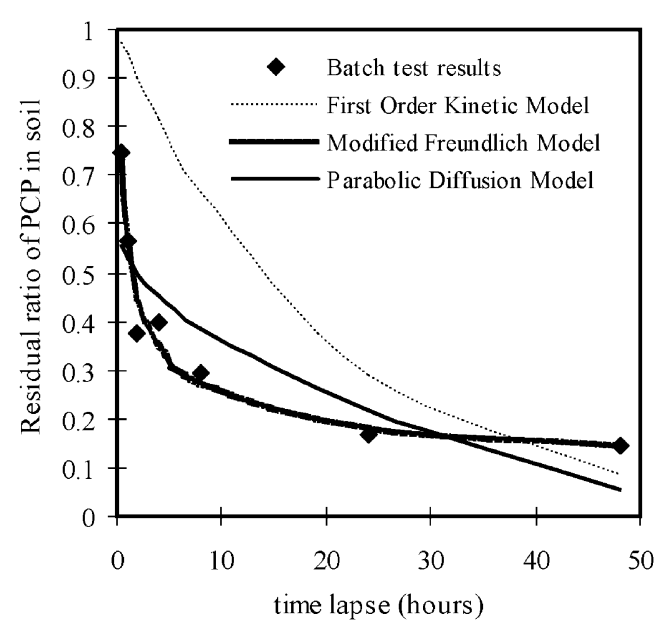

Fig. 3. PCP desorption curve at $T=60^{\circ} \mathrm{C}$.

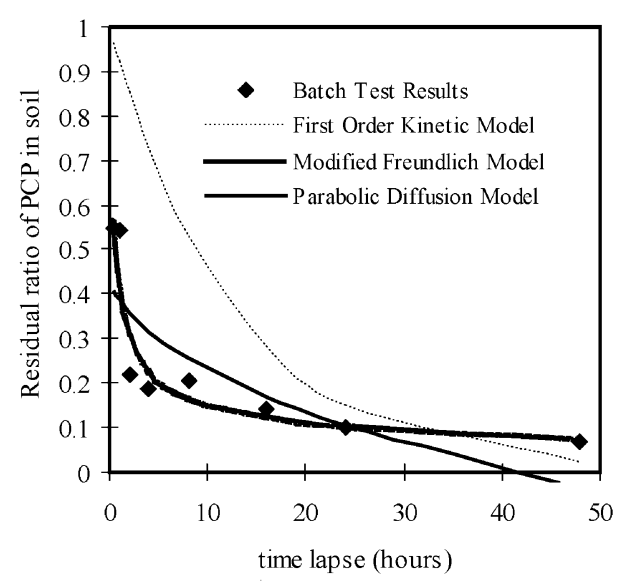

Fig. 4. PCP desorption curve at $T=75^{\circ} \mathrm{C}$.

diffusion-controlled reactions do not control the desorption processes of PCP from the tested soil.

At $30^{\circ} \mathrm{C}$, the parabolic diffusion model fit the experimental data successfully with a $0.9673 r^{2}$ value. However, when the temperature was raised above $45^{\circ} \mathrm{C}$, $r^{2}$ values began to drop below 0.8 . When the temperature was higher than $75^{\circ} \mathrm{C}, r^{2}$ values were less than 0.7. It seemed that the PCP desorption process was diffusion controlled when the temperature was low, but when the temperature was raised, other mechanisms began to control the desorption process.

The modified Freundlich model fit the experimental data well, according to Figs. 1-5 and the $r^{2}$ values listed in Table 2. For all five temperatures, the $r^{2}$ values were more than 0.9 , except at $45^{\circ} \mathrm{C}$ and $90^{\circ} \mathrm{C}$, where the $r^{2}$ values were 0.01 or less than 0.9 . At $60^{\circ} \mathrm{C}, r^{2}$ reached the

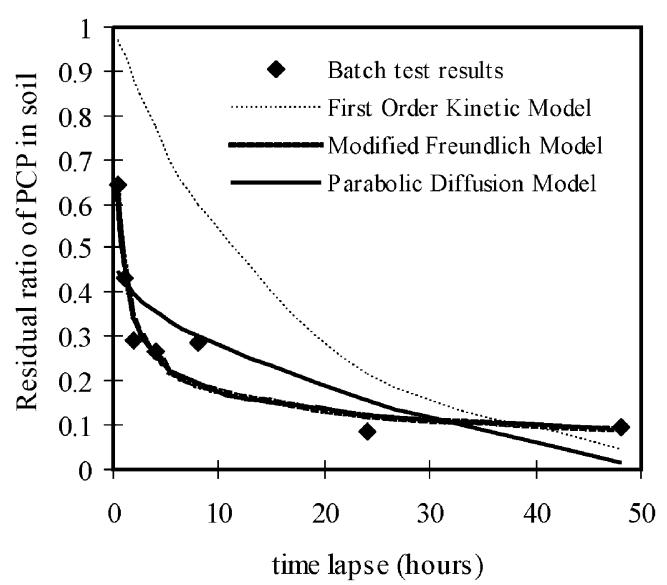

Fig. 5. PCP desorption curve at $T=90^{\circ} \mathrm{C}$.

Table 2

Correlation coefficients $\left(r^{2}\right)$ of three kinetic models at various temperature

\begin{tabular}{llll}
\hline $\begin{array}{l}\text { Temperature } \\
\left({ }^{\circ} \mathrm{C}\right)\end{array}$ & $\begin{array}{l}\text { First order } \\
\text { model }\end{array}$ & $\begin{array}{l}\text { Modified } \\
\text { Freundlich } \\
\text { model }\end{array}$ & $\begin{array}{l}\text { Parabolic } \\
\text { diffusion } \\
\text { model }\end{array}$ \\
\hline 30 & 0.6006 & 0.9213 & 0.9673 \\
45 & 0.6332 & 0.8902 & 0.7632 \\
60 & 0.5624 & 0.9721 & 0.7312 \\
75 & 0.5559 & 0.9217 & 0.6261 \\
90 & 0.5253 & 0.8991 & 0.6878 \\
\hline
\end{tabular}

highest value, 0.9721. Considering the heterogeneous characteristics of field soil and uncertainty caused by human error, the conformity is acceptable [15]. The proposed theory of adsorption energy $[13,10]$ can also explain the PCP desorption from soil. Since the $\mathrm{pH}$ values of the solutions in all tests were close to 7.0, we expected the PCP ions to be the predominant forms. When the PCP ions were initially desorbed from the soil, the adsorption energy increased so that adsorption became unfavorable and the desorption rate became rapid. As the reaction time increased, fewer PCP ions were adsorbed by the soil and perturbation among the adsorbed ions reached a steady state, as did the adsorption energy. The surface negative charge on soil also decreased when more PCP ions were desorbed. Thus, decelerated reaction rates were obvious with increasing time.

Fig. 6 shows the plot of these parameters against temperature and exhibits good linear regression between temperature and model parameters. Substituting the regression equations of $k$ and $m$ in Fig. 6 into the modified Freundlich model, a desorption kinetic 


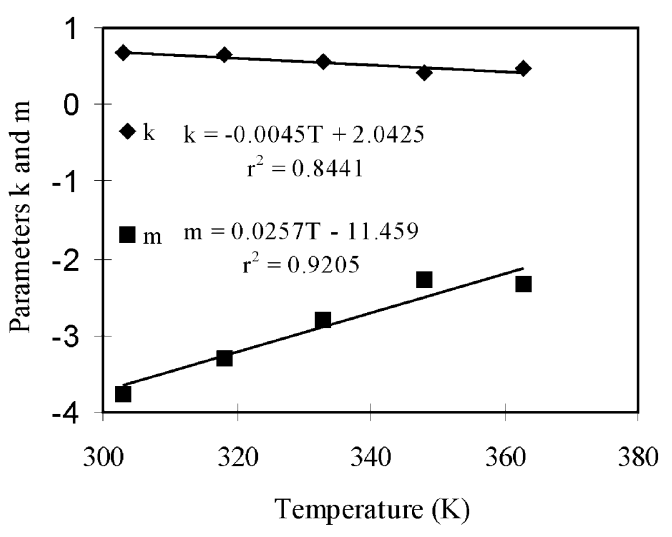

Fig. 6. Temperature vs. modified Freundlich model parameters.

equation, Eq. (9), is obtained:

$X=(2 . \underline{0}-0.004 \underline{4} T) t^{1 /(0.026 T-11)}$,

where $T$ is the absolute temperature. The underlined numbers in each parameter may vary due to the experimental errors.

From the experimental data, desorption was observed to increase with an increase in temperature, indicating an endothermic reaction. The results also confirmed that increased soil and groundwater temperature enhanced desorption of PCP. It was more easily removed by the so-called thermally enhanced pump-and-treatment method.

The characteristics data of the tested soil were substituted into Eq. (3) and the distribution ratio $K$ was calculated to be 13.7 , which was close to the results of the batch tests at $30^{\circ} \mathrm{C}$ at equilibrium, calculated to be 8.1, even though Eq. (3) was derived at a test temperature of $20^{\circ} \mathrm{C}$. We thus confirm Eq. (3) to be a good estimation for $K$ at $20-30^{\circ} \mathrm{C}$.

It is interesting to note that Eq. (9) follows the type of Arrhenius equation in which temperature also appears in the reciprocal of the exponential term, similar to the results of a study on PCP desorption from activated carbon conducted by Mollah and Robinson [7]. The equation relating partition constant $K_{12}$ and free energy [9] is

$\ln K_{12}=-\frac{\Delta G_{12}}{R T}$,

where subscript 1 represents the soil phase and 2 the aqueous phase, and the second law of thermodynamics,

$\Delta G_{12}=\Delta H_{12}-T \Delta S_{12}$

$\frac{\Delta G_{12}}{T}=\Delta H_{12} \frac{1}{T}-\Delta S_{12}$

$R$ is the universal gas constant $(=8.314 \mathrm{~J} / \mathrm{K} / \mathrm{mol})$, and $T$ is the temperature. $\Delta G_{12}, \Delta H_{12}$, and $\Delta S_{12}$ are the

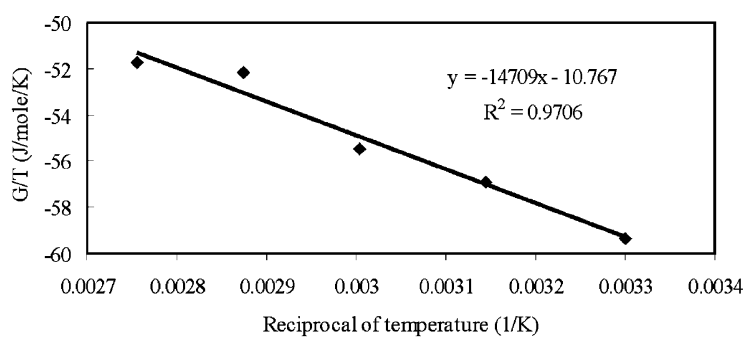

Fig. 7. Free energy of desorption divided by temperature vs. the reciprocal of temperature.

difference of Gibbs free energy, enthalpy, and entropy between the soil phase and aqueous phase. The data in the last two rows of Table 1, representing the concentrations of PCP in the soil and aqueous phases at equilibrium at various temperatures, can be used to calculate the energy change of each form.

The unit of the partition constant is usually $\mathrm{L} / \mathrm{kg}$. To be used in Eq. (10), the partition constant had to be converted to a dimensionless unit by assuming that the density of solution was equal to $1 \mathrm{~kg} / \mathrm{L}$. Furthermore, it was assumed that most of the PCP ions were adsorbed by the organic compounds in soil [9]; as a result, the fraction of organic carbon in soil, 0.0067 , was taken into computation:

$K_{12}=\frac{Q(\mathrm{mg} / \mathrm{kg}) \times 1(\mathrm{~kg} / \mathrm{L})}{C(\mathrm{mg} / \mathrm{L}) \times 0.0067}$.

Fig. 7 was plotted according to Eq. (12). The change of enthalpy and entropy can be read easily from Fig. 7 as $-14.7 \mathrm{~kJ} / \mathrm{mol}$ and $10.8 \mathrm{~J} / \mathrm{mol} / \mathrm{K}$, respectively. To be significant, the partition constant was often used in adsorption reactions [6,9], where the adsorbates in the soil phase were the products and the adsorbates in the aqueous phase were the reactants. The same expression was used in this study for consistence.

The negative enthalpy indicated that an increased temperature favored PCP in the aqueous phase, a similar conclusion to the study of PCP adsorbed by activated carbon [7], in which they found the adsorption energy as $5.2 \mathrm{~kJ} / \mathrm{mol}$. The benefit of groundwater heating was confirmed again. The positive entropy indicates that, in nature, PCP prefers the soil phase to the aqueous phase, and, as a consequence, PCP is difficult to remove from soil in an aquifer.

A field pilot study for steam injection is being conducted in Taiwan. According to the current results of pilot study, we estimated that the full-scale system would cost US\$ $50 / \mathrm{m}^{3}$ of the treated aquifer. The remediation period can be reduced from 13 years using pure pump-and-treat method to 3 years with steam injection system. The total treatment cost may increase 
from US $\$ 500,000$ to US $\$ 2,000,000$. If the treatment cost is acceptable, the advantages of thermal treatment are obvious.

\section{Conclusions}

The desorption batch tests of PCP at various temperatures can be described by a modified Freundlich equation, which indicates that the energy of adsorption increases exponentially with decreasing surface saturation on the soil matrix, or, more precisely, on the organic matter surface, as desorption proceeds.

The decrease in desorption was due to the decreasing negative charges on organic matter, causing the desorption rate to decelerate. The poor results of linear regression by the first-order kinetic model excluded the possibilities of film diffusion control during desorption. The results of linear regression by the parabolic diffusion model indicated that either intraparticle diffusion or surface diffusion may be rate limiting when the desorption temperature is $30^{\circ} \mathrm{C}$. However, when temperature is raised, intraparticle diffusion or surface diffusion becomes less limiting. Desorption of PCP from soil was confirmed to be endothermic, as predicted, that an increasing temperature increases desorption of PCP. Adsorption energy was found to be $14.7 \mathrm{~kJ} / \mathrm{mol}$, a result similar to the adsorption energy of PCP adsorption for activated carbon, $5.2 \mathrm{~kJ} / \mathrm{mol}$, in that they were in the same order. There may be some correlation between these two adsorption energies. Further researches have to be performed to investigate the possibility of correlation. The entropy change indicates that PCP in the soil phase obtains greater thermodynamic freedom and hence PCP prefers the soil phase to the aqueous phase; thus it was difficult to remove PCP from the aquifer. The desorption kinetic equation provided in Eq. (9) will be used in future work on numerical modeling of the thermally enhanced pump-and-treatment method.

\section{References}

[1] Tanjore A, Viraraghavan T. Pentachlorophenol-water pollution impacts and removal technologies. Int $\mathbf{J}$ Environ Studies 1994;45(2):155-64.

[2] US House Committee on Commerce. Half the sites have all cleanup remedies in place or completed, 1999.

[3] Achard C, Jaoui M, Schwing M, Rogalski M. Aqueous solubilities of phenol derivatives by conductivity. J Chem Eng Data 1996;41(3):504-7.

[4] Keyes BR, Silcox GD. Fundamental study of the thermal desorption of toluene from montmorillonite clay particles. Environ Sci Technol 1994;28(5):840-9.

[5] Heron G, Van Zutphen M, Christensen TH, Enfield CG. Soil heating for enhanced remediation of chlorinated solvents: a laboratory study on resistive in a silty, lowpermeable soil contaminated with trichloroethylene. Environ Sci Technol 1998;32(10):1474-81.

[6] You CN, Liu JC. Desorptive behavior of chlorophenols in contaminated soils. Water Sci Technol 1996;33(6):263-70.

[7] Mollah AH, Robinson CW. Pentachlorophenol adsorption and desorption characteristics of granular activated carbon-I. Isotherms. Water Res 1996;30(12):2901-6.

[8] Cristodoulatos C, Mohiuddin M. Generalized models for prediciton of pentachlorophenol adsorption by natural soils. Water Environ Res 1996;68(3):370-8.

[9] Schwarzenbach RP, Gschwend PM, Imboden DM. Environmental organic chemistry. New York: Wiley, 1993.

[10] Kuo S, Lotse EG. Kinetics of phosphate adsorption and desorption by lake sediments. Soil Sci Soc Amer Proc 1974;38:50-4.

[11] Sahoo D, Smith J. Enhanced trichloroethene desorption from long-term contaminated soil using Triton X-100 and pH increases. Environ Sci Technol 1997;31(7):1910-5.

[12] Kithome M, Paul JW, Lavkulich LM, Bomke AA. Kinetics of ammonium adsorption and desorption by the natural zeolite clinoptilolite. Soil Sci Amer J 1998;62: 622-9.

[13] Bache MP, Williams EG. A phosphate sorption index for soils. J Soil Sci 1971;22:289-301.

[14] Tobia RJ, Camacho JM, Augustin P, Griffiths RA, Frederick RM. Washing studies for PCP and creosotecontaminated soil. J Hazard Mater 1994;38(1):145-61.

[15] Fall C, Chaouki J, Chavarie C. Desorptive behavior of pentachlorophenol (PCP) and phenanthrene in soil-water systems. Water Environ Res 2000;72(2):162-9. 